\author{
FEDERAL RESERVE BANK OF SAN FRANCISCO \\ WORKING PAPER SERIES
}

\title{
Parents in a Pandemic Labor Market
}

\author{
Olivia Lofton \\ Nicolas Petrosky-Nadeau \\ Lily Seitelman \\ Federal Reserve Bank of San Francisco \\ February 2021 \\ Working Paper 2021-04
}

https://www.frbsf.org/economic-research/publications/working-papers/2021/04/

\section{Suggested citation:}

Lofton, Olivia, Nicolas Petrosky-Nadeau, Lily Seitelman. "Parents in a Pandemic Labor Market," Federal Reserve Bank of San Francisco Working Paper 2021-04.

https://doi.org/10.24148/wp2021-04

The views in this paper are solely the responsibility of the authors and should not be interpreted as reflecting the views of the Federal Reserve Bank of San Francisco or the Board of Governors of the Federal Reserve System. 


\title{
Parents in a Pandemic Labor Market
}

\author{
Olivia Lofton Nicolas Petrosky-Nadeau Lily Seitelman \\ Federal Reserve Bank of San Francisco*
}

February 4, 2021

\begin{abstract}
Gender gaps in labor market outcomes during the pandemic are largely due to differences across parents: Employment and labor force participation fell much less for fathers as compared to women and non-parent men at the onset of the pandemic; the recovery has been more pronounced for men and women without children, and; the labor force participation rate of mothers has resumed declining following the start of the school year. The latter is partially offset in states with limited school re-openings. Evidence suggests flexibility in setting work schedules offsets some of the adverse impact of the pandemic on mothers' employment, while the ability to work from home does not.
\end{abstract}

JEL Classification: D10, E24, J16, J21

Keywords: Labor supply, work flexibility, childcare, COVID-19

${ }^{*}$ Contact information - Lofton: olivia.lofton@sf.frb.org; Petrosky-Nadeau: nicolas.petroskynadeau@sf.frb.org; Seitelman: lily.seitelman@sf.frb.org. Opinions and conclusions herein are those of the authors and do not necessarily represent the views of the Federal Reserve System and the Federal Reserve Bank of San Francisco. 


\section{Introduction}

Women were hit hardest by the initial wave of pandemic job losses and thus far the labor market recovery has been weaker for women than for men. These gender gaps in labor market outcomes are largely due to differences across parents. Detailed data on primeaged workers from the Current Population Survey (CPS) show employment and labor force participation fell much less for fathers as compared to women and non-parent men during the initial spring 2020 lockdowns to slow the spread of the virus. Moreover, the subsequent recovery in employment and labor force participation has been more pronounced for men and women without children, particularly with the start of the school year. Overall, if mothers had experienced a recovery similar to that of non-parent women, their December labor force participation rate would have been two percentage points above the actual rate. That is, approximately 700 thousand additional prime aged women would have been in the workforce.

Households are likely to have made extensive margin labor supply adjustments to address the particular challenges of providing childcare during the pandemic. While survey evidence points to a large shift towards mothers being the sole provider of childcare since May, even in dual earner households (Zamarro and Prados, 2020), women who remain employed, and mothers in particular, have not reduced the numbers of hours worked on the job during the week. Overall, hours worked on the job decline less for mothers at the onset of the pandemic due to a decline in part time employment. Changes in hours worked for full time mothers and fathers are nearly identical during the pandemic up to the fall when fathers' hours begin to decline relative to mothers'.

These differences, which are robust to controlling for a wide set of demographic characteristics and variation in the intensity of the pandemic across states, mask significant heterogeneity across groups of individuals. The growing gender gaps in employment and participation, for instance, are more pronounced for individuals with the lowest level of education, and those living in lower income households. There does not appear, however, to be a relation between the age of the youngest child in the household and changes in either employment or participation.

One defining aspect of work during a pandemic has been the ability, or lack thereof, to work from home. A second defining aspect of the pandemic has been the widespread disruption to schooling. With schools either fully closed or in some mode of partial in person learning, parents have been required to shift a portion of their available time to supervising their children's education. These responsibilities come into conflict with jobs when work requires a physical presence, but also when there is limited flexibility in work schedules. We complement the degree of teleworkabilty of an occupation with a measure of work flexibility using responses to the American Time Use Survey's (ATUS) leave modules. A job is defined 
as having a flexible schedule if a respondent indicates being able to change their start and end times at least occasionally.

We find that flexibility in setting work schedules offsets some of the adverse impact of the pandemic on mothers' employment, whereas the availability of teleworking does not. That is, in occupations with flexible work schedules, such as management, the ratio of mothers to women's employment did not change significantly during the pandemic. In contrast, occupations with rigid work schedules, such as education, saw pronounced declines in mothers' employment relative to that of women.

Lastly, we examine whether partial reopening of schools relaxes the constraints on parental labor supply decisions combining information form the Census Bureau's Household Pulse Survey (HPS), which provides information on school disruptions at the individual level, and the CPS. In particular, reporting of school disruption is near universal in May 2020 as authorities responded to the onset of the pandemic with school closures and other policies to slow the spread of the virus. By the Fall and the start of the new school year, however, there is wide dispersion in the degree of reported school disruption across states: over 90 percent of parents in California report school disruptions compared to about 40 percent in South Dakota. Although the relation is statistically weak, partial re-openings of schools appear to have alleviated the constraints on mothers' labor supply.

A significant and growing number of papers has documented the gender aspect of a pandemic recession (see, among others, Alon et al., 2020a, Mongey et al., 2020, and Cajner et al., 2020). Women are underrepresented in the occupations with the highest ability to telecommute and in critical occupations (Alon et al., 2020a), and over-represented in occupations requiring physical proximity (Mongey et al., 2020). Women's employment's stronger exposure to the pandemic recession shock appeared confirmed early in the payroll data showing that, even within detailed industries, women were experiencing larger job declines relative to men (Cajner et al., 2020). ${ }^{1}$ The greater impact of the pandemic on women's employment is also documented across countries (Adams-Prassl et al., 2020). Relative to this prior work, we highlight the importance of parental status behind much of the observed gender differences in labor market outcomes during the pandemic.

The unique gender aspect of the pandemic recession, and the role of the provision of childcare, risks longer run consequences on women's labor supply and gender gaps in earnings. According to Dingel et al. (2020), up to a third of the US workforce has children aged 14 or younger in the household, suggesting childcare obligations would hold back the recovery. Alon et al. (2020b) study the macroeconomic implications for women's employment and gender earnings gaps of a recession whose burden falls disproportionately on women. Their

\footnotetext{
${ }^{1}$ Mongey et al. (2020), however, found that women are more likely to be able to work from home. As a result, they expected the overall impact on women's and men's employment to be similar.
} 
model suggests that many of the negative repercussions of a pandemic recession can be averted by prioritizing opening schools and daycare centers during the recovery. Our findings are in line with their work, and adds the importance of flexibility of work schedules to mother's labor supply decisions during a pandemic.

Initial evidence on the link between school closures and parental labor supply is mixed. Amuedo-Dorantes et al. (2020), who focus on the first wave of school closures in April and May 2020, find conflicting effects on mothers and fathers' labor supply. Likewise, Carlson et al. (2020) find equal proportions of fathers and mothers reducing hours or leaving their jobs, though the vast majority did neither. Moreover, Barkowski et al. (2020), who focus on the labor supply of parents with young children during the pandemic, find the likelihood of being employed and at work is not systematically different for men and women, but there is some evidence women with young children working almost an hour longer per week than those without. Heggeness (2020) finds similar results. Our results differ in finding significant differences between men and women conditional on their parental status several months into the pandemic recession as schools failed to re-open for the start of the new school year.

\section{Parents and gender gaps in labor market outcomes}

This section provides a comparison of labor market outcomes for prime-aged men and women overall, and conditional on the presence of a child under the age of 17 living in the household. We refer to the latter groups as parents - mothers and fathers - throughout. Employment, labor force participation (LFP) and hours worked on the job for each group are seasonally adjusted. $^{2}$

\subsection{Employment, Labor force participation, and hours of work}

Employment fell dramatically in April with the onset of the COVID-19 pandemic, but by more for women. Men's employment to population ratio fell 12 percent relative to February. Women's fell 15 percent (Figure 1a). Since then, employment gains for men and women overall have been similar. The gap created at the onset of the pandemic remains. Figure $1 \mathrm{~b}$ reveals these gender differences are driven by parents. Both the initial fall and the subsequent recovery in employment for non-parent men and women were similar (dashed lines). In contrast, the initial fall in employment for fathers was much smaller than for mothers (solid lines) and non-parents. Moreover, the recovery in employment for mothers has stalled since

\footnotetext{
${ }^{2}$ The data are drawn from the Bureau of Labor Statistics' (BLS) Current Population Survey (CPS). The time series for each group are seasonally adjusted and normalized after applying a 3-month moving average. Appendix section A details the sources of and adjustments to the data. To the extent possible we compare our data to that published by the BLS in section A of the supplementary.
} 
mid-summer as compared to fathers and non-parents. Fathers' employment to population ratio fell 10 percent relative to February, while it fell 15 percent for mothers. Fathers were 4 percent below their pre-pandemic employment to population ratio in December while mothers were 7 percent below. In sum, there has been a rising gender employment gap since the start of the school year for parents, and not for non-parents.

Participation in the labor market tells a similar but even starker story. After sharp declines in April, labor force participation rates of prime age men and women had recovered half of their earlier declines by mid-summer (Figure 1c). Since July, men's participation rate has remained at the same level while women's participation fell again to around 3 percent below its pre-pandemic level. Figure 1d reveals that, once again, the differences are driven by parents. The patterns in labor force participation of non-parent women and men are similar, and both are slightly below pre-pandemic rates in December (dashed lines). Mothers' participation in the labor market fell 5 percent from its pre-pandemic level in April, partially recovered during the summer, yet fell back again to April lows with the start of the new school year. ${ }^{3}$

The particular challenges facing households during the pandemic have led to adjustments in time allocations across tasks. Survey evidence points to a large shift towards mothers being the sole provider of childcare since May, even in dual earner households (Zamarro and Prados, 2020), possibly leading to a change in the number of weekly hours worked for those employed. Figure 1e reports changes in average weekly hours worked on the job for women and men during the pandemic. Adjustments in weekly hours worked have been modest, similar to previous business cycles. Men's and women's average hours worked fell by similar amounts at the beginning of the pandemic. Women's hours worked were back to pre-pandemic levels at the end of the year while men's hours have remained around 2 percent below pre-pandemic levels since September. Hours worked fell the least for mothers at the start of the pandemic, due to a pronounced decline in part time employment coinciding with the initial wave of school closures. ${ }^{4}$ The gap in hours between mothers and the remaining groups closed over the subsequent months. A gap appeared again starting in September that separated instead men and women independent of parental status.

Table 1 reports February and December 2020 employment to population ratios and labor force participation rates, the proportional change between the two months, and contributions of sub-group changes in either employment to population ratios or labor force participation

\footnotetext{
${ }^{3}$ Seasonality appears to play some amplifying role in the rise and fall in mothers' labor force participation rates at over the summer months. This can be been in a supplemental appendix which plots the equivalent chart using the non-seasonally adjusted data.

${ }^{4}$ See appendix Figure A3a for a breakdown of mothers' employment during the pandemic. The path for hours worked is similar for all genders and parental groups conditional on full time employment, as shown in appendix Figure A2.
} 


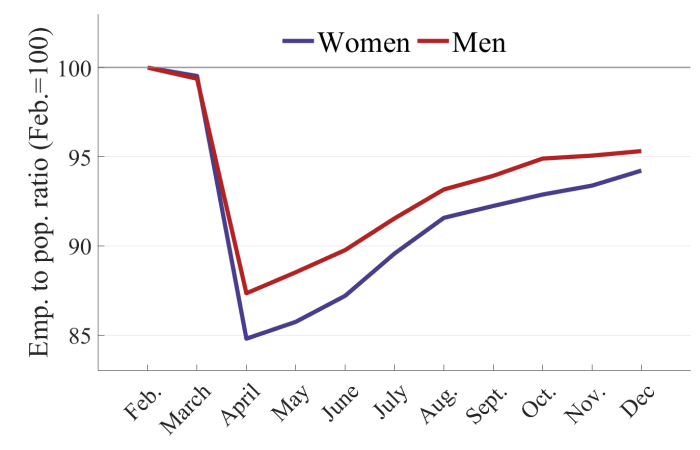

(a) Employment to population ratio

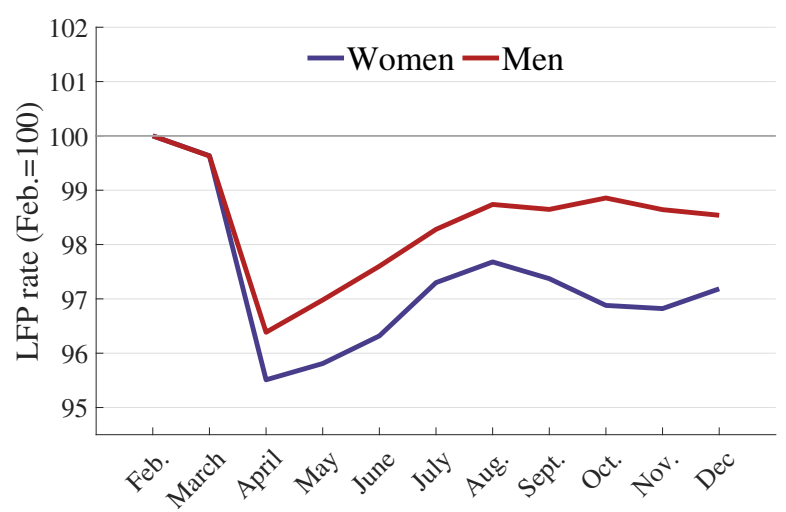

(c) Labor force participation rate

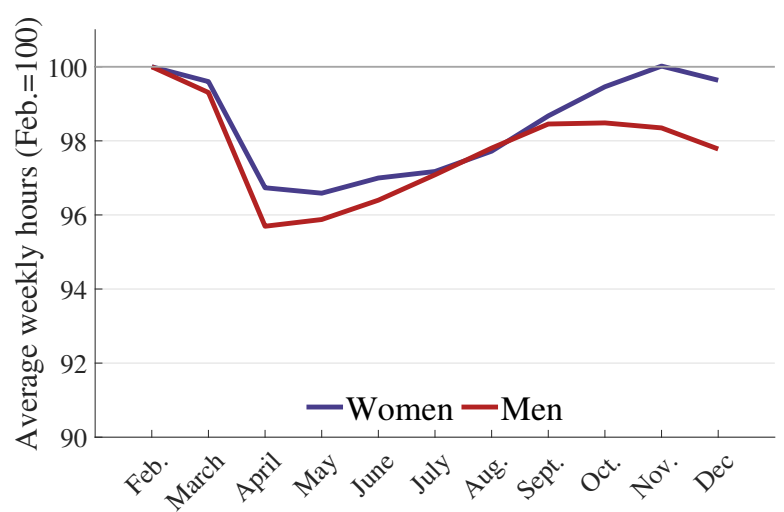

(e) Hours worked per week

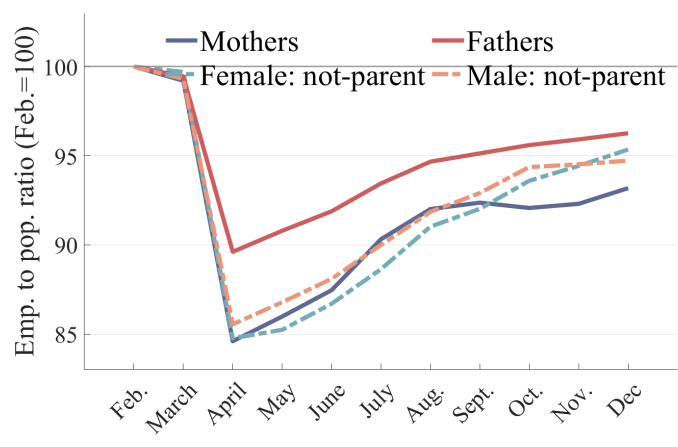

(b) Employment to populatio ratios

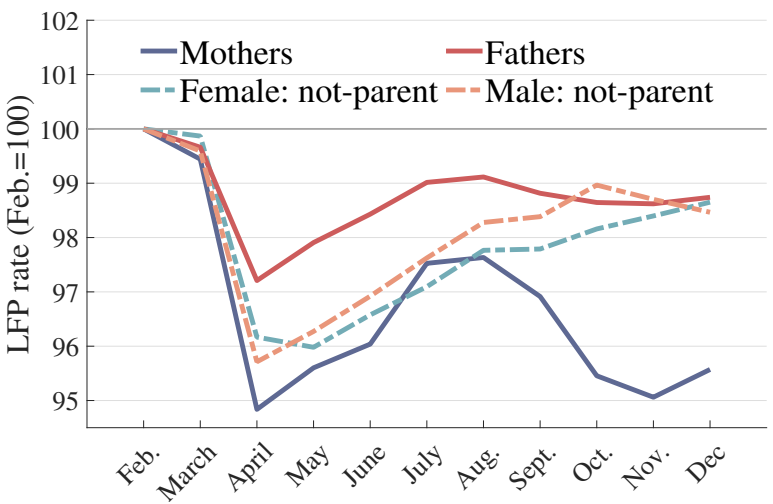

(d) Labor force participation rates

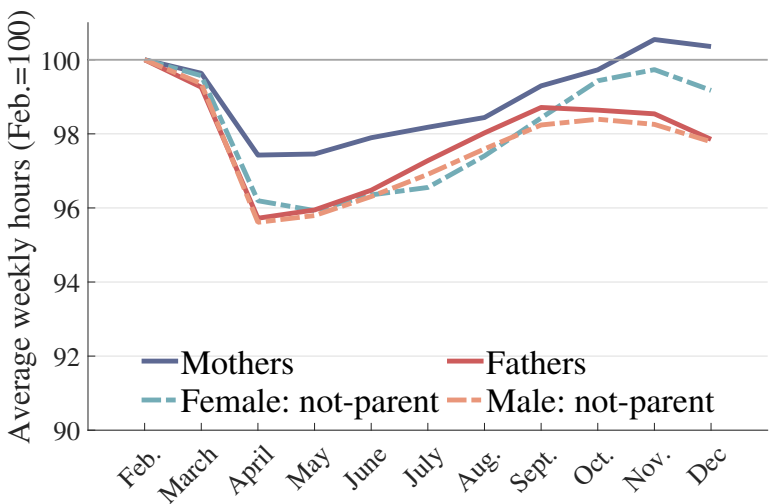

(f) Hours worked per week

Figure 1: Employment to population ratios, labor force participation rates and hours worked per week for prime aged women and men, and conditional on the presence of a child under the age of 17. Normalized to Feb. 2020.

Note: Authors' calculations using data from the Current Population Survey. Parental status indicates the presence of a child under the age of 17 years old in the household. 3-month moving average on seasonally adjusted data, see data appendix for details. 
rates to the change in the group's corresponding outcome during the pandemic. ${ }^{5}$ Mothers account for about half of the 5 percentage point decline in women's employment to population ratio, and nearly three quarters of the 2 percentage point decline in women's LFP rate. Fathers account for about one-third of the 4 percentage point decline in men's employment to population ratio and of the 1 percentage point decline in men's LFP rate. If mothers had experienced a recovery similar to that of non-parent women, their December labor force participation rate would have been approximately 73 percent, two percentage points above the actual rate. That is, approximately 700 thousand additional prime aged women would have been in the workforce in December 2020.

The disproportionate burden of the pandemic recession on women, especially mothers, contrasts sharply with the situation of the Great Recession, which many commentators at the time described as a "mancession." 6 The employment to population ratio and labor force participation rates for men, especially non-parent men, fell more than that of women during the three years covering the Great Recession and the initial recovery period. The paths for mothers and fathers were similar overall, with fathers faring slightly worse during the first couple years of that period.

\subsection{Differences across demographic groups}

Labor market outcomes vary significantly across demographic groups during recessions in general, and a pandemic recession in particular. This section first considers differences in employment to population ratios and labor force participation rates within and then controlling for different demographic characteristics.

The pandemic has affected individuals with the lowest levels of education hardest, and this is all the more apparent when comparing mothers and fathers in the labor market (see Table 1). The fall in employment to population ratios and labor force participation rates of mothers is twice as large for mothers with a high school education or less compared to college educated mothers. However, due to their high employment and labor force participation rates, college educated mothers contribute about one third to the changes in the employment to population ratio and LFP rate of mothers as a group even though they experienced the smallest declines in employment and labor force participation rates (see middle rows of Table 1). This is not the case among fathers. Employment loss and declines in labor force participation for fathers is concentrated among those with a high school education or less. In sharp contrast, nonparent men and women with more than a high school education experienced similar declines

\footnotetext{
${ }^{5}$ We calculate group $i$ 's contribution to the change in say, LFPR, of population $j$, as $\left[\omega_{i, t}^{j}\left(l f_{i, t}^{j}-l f_{i, t-1}^{j}\right)\right] /\left[l f_{t}^{j}-l f_{t-1}^{j}\right]$ where $\omega_{i, t}^{j}$ is group $i$ 's share in the population $j$.

${ }^{6}$ This contrast can be seen clearly in Figure A4 which reproduces the charts in Figure 1 for employment to population ratios and labor force participation rates between Dec. 2007 and Dec. 2015.
} 
Table 1: Changes in employment to population ratios and participation rates

\begin{tabular}{|c|c|c|c|c|c|c|c|c|}
\hline & \multicolumn{4}{|c|}{ Emp. pop. (\%) } & \multicolumn{4}{|c|}{$\operatorname{LFPR}(\%)$} \\
\hline & Feb. & Dec. & $\Delta$ & ctr. & Feb. & Dec. & $\Delta$ & ctr. \\
\hline Women & 74.9 & 70.6 & -5.8 & & 77.2 & 75 & -2.8 & \\
\hline Parent & 72.2 & 67.3 & -6.8 & 55.9 & 74.5 & 71.2 & -4.4 & 72.9 \\
\hline Non-parent & 77.5 & 73.9 & -4.6 & 41.6 & 79.7 & 78.7 & -1.3 & 22.4 \\
\hline Men & 86.5 & 82.5 & -4.7 & & 89.2 & 87.9 & -1.5 & \\
\hline Parent & 92.5 & 89 & -3.7 & 33.9 & 94.6 & 93.4 & -1.3 & 32.0 \\
\hline Non-parent & 82.3 & 78 & -5.3 & 65.6 & 85.4 & 84.1 & -1.5 & 69.2 \\
\hline \multicolumn{9}{|l|}{ Mothers } \\
\hline \multicolumn{9}{|l|}{ Education: } \\
\hline HS & 60.2 & 54 & -10.3 & 40.6 & 63.8 & 59.9 & -6.2 & 37.9 \\
\hline Some college & 73.2 & 68.3 & -6.7 & 27.2 & 75.8 & 72.9 & -3.9 & 26.3 \\
\hline College and above & 80.1 & 76.3 & -4.8 & 35.9 & 81.6 & 79 & -3.2 & 39.3 \\
\hline \multicolumn{9}{|l|}{ Age of youngest child: } \\
\hline 5 years and younger & 66.6 & 61.9 & -6.9 & 41.1 & 68.9 & 65.7 & -4.7 & 44.1 \\
\hline 6 to 13 years old & 75.4 & 70.3 & -6.7 & 43.1 & 78.1 & 74.8 & -4.2 & 44.3 \\
\hline 14 to 17 years old & 78.4 & 72.9 & -6.9 & 20.8 & 80.8 & 77 & -4.7 & 21.6 \\
\hline \multicolumn{9}{|l|}{ Household income: } \\
\hline Less than $\$ 50,000$ & 55.2 & 48.1 & -12.8 & 42.4 & 59.4 & 54.9 & -7.4 & 40.6 \\
\hline$\$ 50,000$ to $\$ 99,999$ & 72.8 & 68.1 & -6.4 & 26.6 & 74.6 & 71.7 & -4.0 & 25.7 \\
\hline$\$ 100,000$ and above & 80.8 & 78.0 & -3.5 & 22.7 & 81.8 & 80.0 & -2.2 & 24.2 \\
\hline \multicolumn{9}{|l|}{ Fathers } \\
\hline \multicolumn{9}{|l|}{ Education: } \\
\hline HS & 89.3 & 84.9 & -5 & 48.7 & 92.8 & 91.1 & -1.8 & 66.7 \\
\hline Some college & 91.7 & 86.5 & -5.6 & 33.9 & 93.2 & 91.4 & -1.9 & 40.3 \\
\hline College and above & 95.6 & 94.3 & -1.4 & 16.2 & 96.9 & 96.8 & -.1 & 3.9 \\
\hline \multicolumn{9}{|l|}{ Age of youngest child: } \\
\hline 5 years and younger & 93.4 & 89.3 & -4.4 & 55.4 & 95.4 & 93.7 & -1.7 & 71.9 \\
\hline 6 to 13 years old & 91.9 & 88.6 & -3.6 & 39.1 & 94.2 & 93 & -1.2 & 53.9 \\
\hline 14 to 17 years old & 91.1 & 89.2 & -2.1 & 7.0 & 92.9 & 93.2 & .4 & -4.9 \\
\hline \multicolumn{9}{|l|}{ Household income: } \\
\hline Less than $\$ 50,000$ & 84.3 & 78.8 & -6.5 & 43.7 & 88.9 & 87.8 & -1.2 & 18.4 \\
\hline$\$ 50,000$ to $\$ 99,999$ & 93.7 & 90.5 & -3.4 & 27.7 & 95.4 & 94.1 & -1.4 & 18.4 \\
\hline$\$ 100,000$ and above & 96.8 & 95.1 & -1.8 & 21.3 & 97.7 & 97.0 & -0.7 & 22.9 \\
\hline
\end{tabular}

Notes: Authors' calculations using data from the Current Population Survey. A 3-month moving average is applied to the seasonally adjusted data, see data appendix for details. $\Delta$ measures the proportional change between Feb. and Dec. 2020. "ctr.": contribution a subgroup's change in either employment to population ratio or labor force participation rate made to the change in a group's ratio or rate between Feb. and Dec. 2020. 
in employment. ${ }^{7}$

The disparate gender and parental labor market impacts of the pandemic is evident across the household income distribution as well. In the results reported here we restrict the population to households with two or more adults, and sort individuals into household income terciles as defined by the distribution of household income prior to the onset of the pandemic. $^{8}$ Mothers in the bottom tercile experienced job losses 5 times larger than mothers in the highest household income tercile. Similarly, the decline in labor force participation is much stronger in the bottom household income tercile. In sharp contrast, the decline in employment for fathers is half that of mothers in the bottom household income tercile. Moreover, mothers in the bottom household income tercile contribute the most to the decline in mothers' employment and labor force participation rates, about two thirds, which is not the case among fathers.

Lastly, changes in employment to population ratios and LFP rates for parents according to age of the youngest child in the household are reported in the bottom rows of Table 1. There does not appear to be a correlation between the age of the youngest child at home and changes in either employment to population ratios or labor force participation rates of mothers. This is mirrored in the contributions of each age group to the overall changes in mothers' employment to population ratio and labor force participation rate. The reduction in employment to population ratios and labor force participation rates appears, however, to be more pronounced for fathers with younger children.

In order to better control for the different demographic characteristics of parents in explaining the gender gaps in participation during the pandemic, we specify the probability in month $t$ of being in the labor force for prime age men and women as a logit:

$$
l f p r_{t}=\frac{\exp \left(X^{\prime} \gamma_{t}+\alpha_{t} \times \text { Child } \times \text { Sex }\right)}{1+\exp \left(X^{\prime} \gamma_{t}+\alpha_{t} \times \text { Child } \times \text { Sex }\right)}
$$

where the vector $X$ contains the characteristics of age, race/ethnicity, education, marital status, as well as a control for state of residence. The impact of the presence of a child in the household on the likelihood of participating in the labor market is captured with the indicator function Child $=1$ if there is at least one child under the age of 17 in the household. We include all prime-aged women and men in February and November 2020 in our sample and estimate the logits for both months jointly with the addition of a month dummy variable. The estimated coefficients are available in Table A1.

\footnotetext{
${ }^{7}$ Figure A1 compares the proportional changes in employment to population ratios and labor force participation rates of parents and non-parents by level of education, for three groups of parents according to the age of the youngest child in the household, and by household income tercile.

${ }^{8}$ Restricting the population to households with two or more adults does not materially affect the results. The corresponding results using the full sample of prime age workers are reported in appendix Table A3.
} 
Table 2: Labor force participation regressions: predicted change between Feb. and Nov. 2020 for prime aged women and men and by parental status

\begin{tabular}{|c|c|c|c|c|c|c|c|c|}
\hline & \multicolumn{2}{|c|}{ (1) } & \multicolumn{2}{|c|}{$(2)$} & \multicolumn{2}{|c|}{$(2)$} & \multicolumn{2}{|c|}{ (4) } \\
\hline & women & men & women & men & women & men & women & men \\
\hline \multicolumn{9}{|c|}{ Proportional change } \\
\hline no child & $-1.4^{*}$ & $-2.4^{* * *}$ & $-1.4^{*}$ & $-2.4^{* * *}$ & $-1.8^{* *}$ & $-2.3^{* * *}$ & $-1.8^{* *}$ & $-2.4^{* * *}$ \\
\hline child & $-3.3^{* * *}$ & -.6 & $-3.2^{* * *}$ & -.6 & $-3.0^{* * *}$ & -.5 & $-3.0^{* * *}$ & -.5 \\
\hline \multicolumn{9}{|c|}{ Difference (women vs. men) } \\
\hline no child & \multicolumn{2}{|c|}{-1.0} & \multicolumn{2}{|c|}{-.9} & \multicolumn{2}{|c|}{-.6} & \multicolumn{2}{|c|}{-.6} \\
\hline child & \multicolumn{2}{|c|}{$2.7^{* * *}$} & \multicolumn{2}{|c|}{$2.6^{* * *}$} & \multicolumn{2}{|c|}{$2.5^{* *}$} & \multicolumn{2}{|c|}{$2.5^{* *}$} \\
\hline Age & \multicolumn{2}{|c|}{ No } & \multicolumn{2}{|c|}{ Yes } & \multicolumn{2}{|c|}{ Yes } & \multicolumn{2}{|c|}{ Yes } \\
\hline Education & \multicolumn{2}{|c|}{ No } & \multicolumn{2}{|c|}{ No } & \multicolumn{2}{|c|}{ Yes } & \multicolumn{2}{|c|}{ Yes } \\
\hline Race/ethnicity & \multicolumn{2}{|c|}{ No } & \multicolumn{2}{|c|}{ No } & \multicolumn{2}{|c|}{ No } & \multicolumn{2}{|c|}{ Yes } \\
\hline Marital status & \multicolumn{2}{|c|}{ No } & \multicolumn{2}{|c|}{ No } & \multicolumn{2}{|c|}{ No } & \multicolumn{2}{|c|}{ Yes } \\
\hline State fixed effects & \multicolumn{2}{|c|}{ No } & \multicolumn{2}{|c|}{ Yes } & \multicolumn{2}{|c|}{ Yes } & \multicolumn{2}{|c|}{ Yes } \\
\hline
\end{tabular}

Notes: Statistical significance at the 1,5 , and 10 percent levels indicated by $\left({ }^{* * *}\right),\left({ }^{* *}\right)$, and $\left({ }^{*}\right)$ respectively. Sample size: 85,765

The estimated model is used to predict the proportional change in labor force participation rates between February and November 2020 for men and women by parental status, and controlling for demographics and state fixed effects. The results are presented in the first two rows of Table 2. The following two rows present the difference in the proportional changes to participation for women compared to men and by parental status, and tests for the significance of the difference. The regressions confirm that, after controlling for the presence of a child, prime aged women and men experienced similar declines in labor force participation rates (the gap in proportional declines is not significant for non-parents). The gap remains and is significant for parents. In sum, the gender participation gap in November is almost entirely explained by the labor market experience of parents even after controlling for demographic characteristics and state fixed effects.

\section{Remote work, work flexibility and employment in a pandemic}

Pandemic related health measures have placed constraints on in person work, while the additional childcare burden of school and daycare closures have placed greater importance on the ability to set work schedules. We examine the relation between the ability to do work 
from home, flexibility in setting work schedules, and changes in parental employment within major occupations during the pandemic.

\subsection{Ability to work remotely and to set schedules by occupation}

The American Time Use Survey (ATUS) provides information on the availability and use of telework by employed individuals. In addition, the ATUS Leave Module provides information on whether a person is able to flexibly set their work start and end times. We use this information to estimate the share of jobs within an occupation that can be done at home and that afford workers flexibility to set their work hours. That is, the flexibility of work scheduling in an occupation is the share of individuals reporting being able to set their start and end times at least occasionally, while the share of jobs that can be done at home is the proportion of individuals who indicated being able to telework. ${ }^{9}$

The first two columns of Table A2 report these shares for 22 major occupations, sorted by their respective flexibility score, along with the distributions of men and women's employment across occupations. Women's employment is more equally distributed across the range of work flexibility scores than men's. For men's employment, 41 percent is in occupations with over 60 percent of jobs reporting scheduling flexibility, and 44 percent of their employment is in an occupation with a measure of teleworkability below 40. The corresponding employment shares for women are 34 and 36 percent, respectively. Men's employment is more concentrated in occupations with the lowest ability to work from: 50 percent of their employment is in an occupation reporting less than 20 percent of jobs that can be done from home. The corresponding share for women is 37 percent. However, men also have a greater share of employment in occupations with high ability to work from home: 32 percent compared to 26 percent of women's employment.

Occupations with the greatest ability to set work schedules tend to also have the highest ability to work from home, and the proportion of the two dimensions are similar for these occupations. For instance, 68 percent of individuals in architecture and engineering can work from home, and 72 percent report flexibility in setting their work schedule. ${ }^{10}$ As the proportion of jobs that can be done from home declines in an occupation, so too does the amount of work flexibility but to a lesser degree. Workers in food preparation occupations for instance cannot do their jobs from home (2 percent) but have a relatively high degree of

\footnotetext{
${ }^{9}$ The measure of jobs that can be done from home is somewhat different than constructed by Dingel and Neiman (2020). The ranking of occupations by ability to work from home is similar, yet there are a few significant differences. Education, for instance, has a much higher share of jobs that can be done from home in their measure compared to ours. See the data appendix for a more detailed discussion of the difference.

${ }^{10}$ Figure A5 of the appendix plot share of jobs that can be done from home against the measure of work flexibility by occupation, and weights the size of the markers by the distribution of women's employment across occupations.
} 
work flexibility. Around 45 percent report being able to set their work schedules. Finally, education and related occupations are an important outlier with a relatively high ability to work remotely (nearly 40 percent) but a very low ability to set work schedules.

\subsection{Parental employment, telework and flexibility}

The ability to telework has, generally, cushioned the pandemic's impact on employment. That is occupations with the greatest shares of jobs that can be done from home experienced the least job loss at the onset of the pandemic (see Table A2). We examine whether the ability to work from home has allowed mothers to remain employed during the pandemic more than otherwise before looking at the importance of flexibility in scheduling work hours.

Denote the share of parent to overall employment within an occupation by gender $\kappa_{i, t}^{j, p} \equiv$ $E_{i, t}^{j, p} / E_{i, t}^{j}$ where $p$ indicates a parent, $j=$ women, men, and $i$ an occupation. Table A2 provides the values of $\kappa_{i, t}^{p}$ prior to the pandemic and over the most recent months (averaging Oct. through Dec., 2020). We compare the change in $\kappa_{i, t}^{j, p}$ over these two periods to the share of jobs that can be done from home in occupation $i$ for mothers in Figure 2a, and for fathers in Figure 2b. Each figure also includes a regression line weighted by the gender distribution of employment across occupations prior to the pandemic. The ability to perform work at home appears to have not meaningfully changed employment outcomes for mothers, nor for fathers.

Flexible working hours, however, may have limited the decline in employment of mothers during the pandemic in a way that the ability to work from home could not. Occupations with higher shares of jobs with rigid work schedules experienced the largest declines in employment of mothers relative to women without children at home. That is, in occupations with flexible work schedules, such as management, the ratio of mothers to women's employment did not change significantly during the pandemic. In contrast, occupations with rigid work schedules, such as education, saw pronounced declines in mothers' employment relative to women's employment (see Figure 2c). Fathers saw comparatively modest employment gains relative to non-fathers in occupations with great work schedule flexibility.

The finding of a strong correlation between mothers' employment and work flexibility suggest the ability to set working hours is of greater importance during a pandemic than the ability to work from home when childcare hours are relatively inflexible (remote schooling, for instance, takes place during a rigid time-frame). Mothers, in contrast with fathers, cannot take advantage of jobs that can be done from home if they are unable to set their work schedules. 


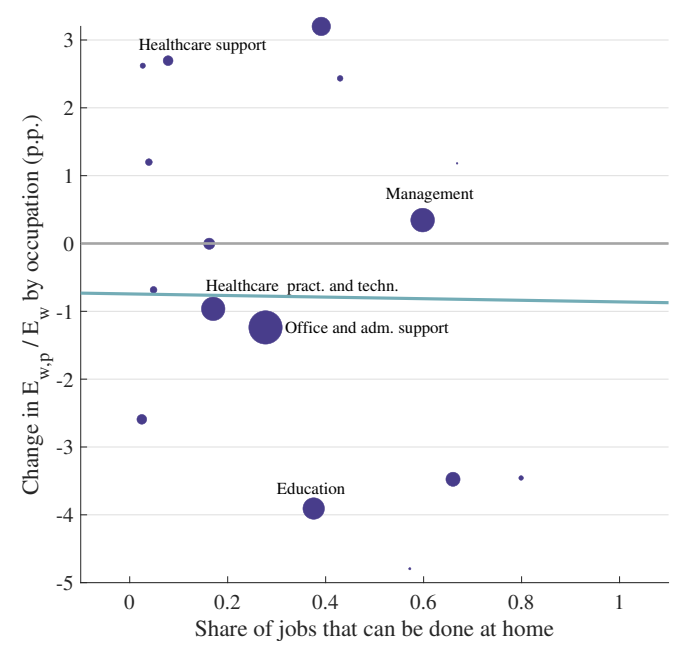

(a) Work from home: Women

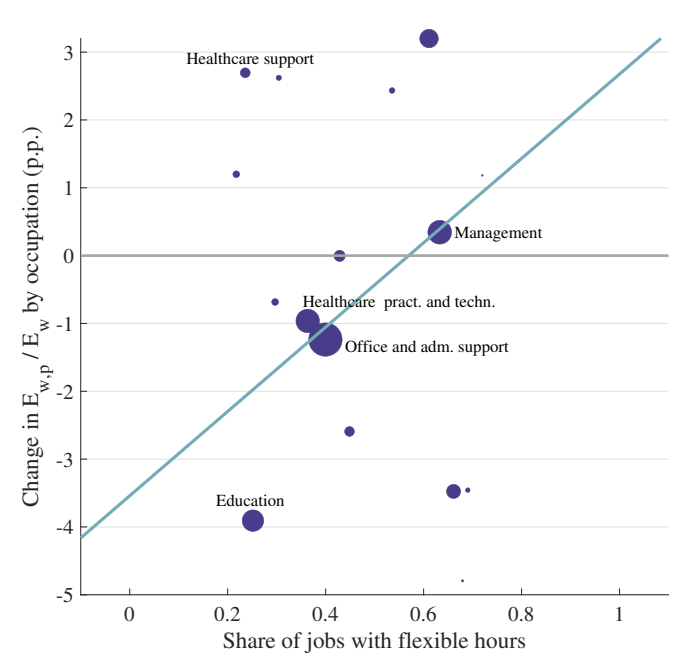

(c) Work flexibility: Women

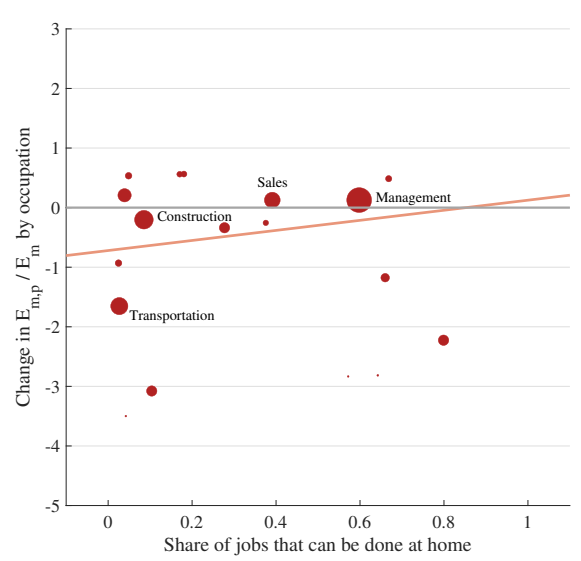

(b) Work from home: Men

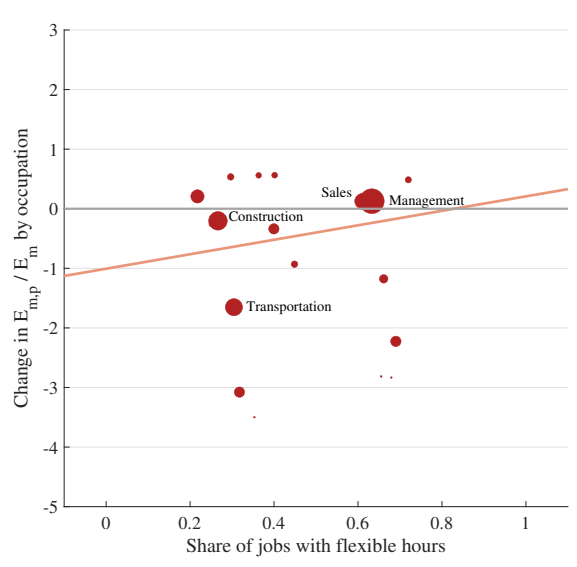

(d) Work flexibility: Men

Figure 2: Changes in within occupation ratios of parent to non-parent employment by gender (pre-pandemic and fall of 2020) against (i) the share of jobs that can be done from home, and (ii) the share of jobs with a flexible work schedule.

Note: Authors' calculations using data from the Current Population Survey and the American Time Use Survey Leave Module. Seasonally adjusted, see appendix for additional details. Regression line weighted by the gender distribution of employment across occupations. 


\section{School closures and labor supply}

Survey evidence points to a large shift towards mothers being the sole provider of childcare since May when schools shut down across the US as part of the initial attempts to slow the spread of the COVID-19 virus (Zamarro and Prados, 2020). Nonetheless, as seen above, women who remain employed, and mothers in particular, have not reduced the numbers of hours worked on the job during the week. Households made extensive margin labor supply adjustments to address the childcare needs of the pandemic. This section uses data from the Census Bureau's Household Pulse Survey (HPS) in conjunction with the monthly CPS to asses whether school re-opening during the fall has relaxed constraints on parental labor supply.

\subsection{Data on school closures}

In April 2020 the Census began conducting the HPS to assess the impact of the pandemic on U.S. households. ${ }^{11}$ Households with a child enrolled in school during the 2020-2021 school year are asked whether the pandemic has impacted schooling during the school year and if it has, the survey asks for details on the nature of the disruptions (canceled in person teaching, a move to distance learning, whether learning is done online or on paper, or by some other means).

The proportion of respondents with an enrolled child in a state reporting a school disruption provides a monthly state level school disruption index $\psi_{s, t} \in(0,1)$. A value of $\psi_{s, t}=0$ indicates that no school disruptions are reported in state $s$ at date $t{ }^{12}$ Figure 3 a plots the state level school disruption indices from May through November, highlighting five states: California, New York, Texas, Iowa and South Dakota. The school disruption indices are close to 1 in all states in May as states responded to the onset of the pandemic with school closures and other policies to slow the spread of the virus. By the Fall and the start of the new school year there is wide dispersion in the degree of reported school disruption across states: over 90 percent of parents in California report school disruptions compared to about 40 percent in South Dakota.

\footnotetext{
${ }^{11}$ The HPS set out to cover a broad set of topics including employment, food security, physical and mental health, disruption to education, access to benefits, financial health and ability to tele-work, among others. The HPS samples just over a million household units, with about 100k respondents in the weekly samples after week 2 during phase 1 (April 23 to July 16), about 100k respondents during phase 2 (covering Aug. 19 to Oct. 26), and 70k respondents during phase 3 (Oct. 28 to Dec. 7). The HPS school disruption question applies to respondents with a child enrolled in a public school, enrolled in a private school, or educated in a homeschool setting.

${ }^{12}$ We use the survey week corresponding to, or closest to, the CPS reference week for the month when constructing the monthly school disruption indices. It is worth noting one concern with the phrasing of the school disruption question in the HPS: it is not clear whether individuals are reporting disruptions current to the survey week, or at any point during the pandemic to date.
} 


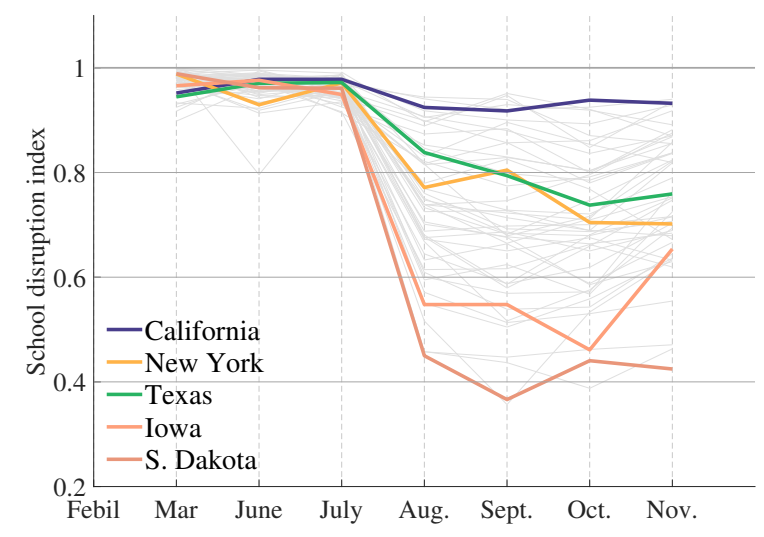

(a) State level rates of reported school disruptions, May through Nov. 2020

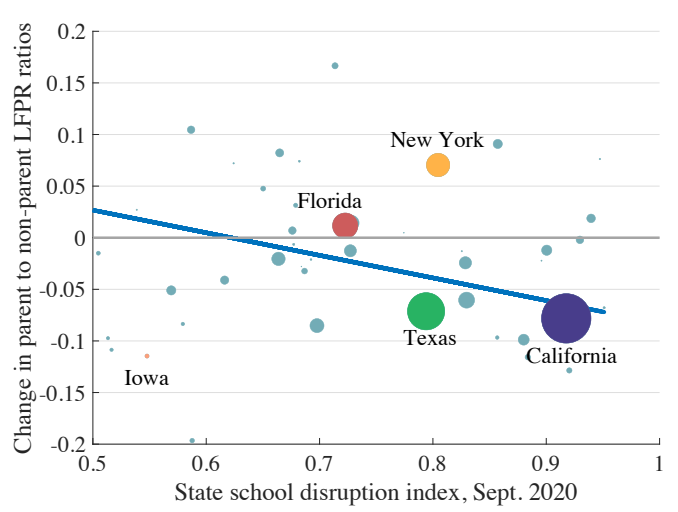

(b) School disruptions and changes in ratios

Figure 3: Women's labor force participation and school re-openings: State level school disruptions rates (a) and the change in relative LFPR against school disruptions in Sept. 2020 (b).

Note: Authors' calculations using data from the Current Population Survey and Household Pulse Survey. Seasonally adjusted. Regression line weighted by the distribution of employment across states.

\subsection{Impact on LFPR: Broad patterns}

In order to assess whether a partial reopening of schools relaxes the constraints on parental labor supply decisions we examine the relation between the state level index of school disruption and parental labor force participation. ${ }^{13}$ In particular, we use a measure of participation in the labor market for parents relative to non-parents by state $(s)$ to control for differences in the severity of the pandemic's economic impact across states:

$$
\phi_{i, t}^{s}=\left(\frac{l f_{i, t}^{s}}{l f_{i^{\prime}, t}^{s}}\right)
$$

where $i=$ mothers, fathers and $i^{\prime}$ are the corresponding non-parent women or men. We then look at the evolution of relative parental labor force participation compared to a benchmark at the onset of the pandemic $\left(\phi_{i, 0}^{s}\right)$ in a given state:

$$
\Phi_{i, t}^{s}=\phi_{i, t}^{s}-\phi_{i, 0}^{s}
$$

against the state's measure of school disruption during the fall of 2020. The benchmark $\phi_{i, 0}^{s}$ and the fall $\phi_{i, t}^{s}$ average two months of data to address small sample sizes in the CPS when working at the state level. In most states, non-parent women's LFPR rates have recovered

\footnotetext{
${ }^{13}$ An earlier study of COVID-19 school closures and parental labor supply in the US, Amuedo-Dorantes et al. (2020), focusing on April-May closures found conflicting effects.
} 
more than those of mothers between the initial months of the pandemic (April-May) and the fall (October-November). ${ }^{14}$ In California, for instance, the ratio fell from 90 to 83 percent. However in a few states, mothers' LFP rates rose faster, such as in New York where the ratio increased from 85 to 92 percent.

Overall there appears to be a negative relation between the degree of school disruption in the fall of 2020 and the change in mothers' labor force participation rates relative to that of non-parent women within the same state since the first months of the pandemic. Figure $3 \mathrm{~b}$ plots the change in relative labor force participation rates $\Phi_{i, t}^{s}$ against state's measure of school disruption. In California, one of the highest school disruption states, the ratio of mothers' to non-parent women's LFP rate fell 7 percentage points. In Florida, a state reporting partial re-opening of schools, the same ratio increased 1 percentage point. The same figure also includes a regression line weighted by the distribution of employment across states.

\section{Conclusion}

A pandemic recession separates parents from the rest in the workforce, and adversely affects mothers in particular as the virus' effects on society persist. Prime age men and women without a child in the household experienced broadly similar labor market dynamics from the onset of the pandemic through the recovery to date. Prime aged men with a child at home, in contrast, fared better than all. Prime aged women with a child at home experienced significant job loss and a weaker labor market recovery. In addition, flexibility in work schedules appears to have provided a better cushion to remain employed than the ability to work from home for mothers. This is likely due to the inflexibility of childcare hours during periods of remote school. Indeed, states with fewer reported disruptions to schooling in the 2020-2021 school year saw moderately better improvements in labor force participation of mother relative to other women.

If the pandemic persists, further delaying a return of women with children to the labor market, there is a risk of labor market scarring affecting the future earnings potential and reducing the number of mothers who eventually return to work. Moreover, household behavioral adaptations may persist beyond the recession, preventing a full recovery in labor market attachment of the cohort of mothers affected by the pandemic. Finally, the lack of childcare support and flexibility laid bare by the pandemic may affect the labor supply decisions of incoming cohorts of parents, with long lasting implications for the gender labor

\footnotetext{
${ }^{14}$ Figure A6b of the appendix plots the ratios $\phi_{i, t}^{s}$ for women in each state at the start of the pandemic against their values in fall of 2020. States below the 45 degree line saw a decline in mothers' labor force participation rate relative to women without a child at home.
} 
force participation, employment and earnings gaps.

\section{References}

Adams-Prassl, Abi, Teodora Boneva, Marta Golin, and Christopher Rauh, "Inequality in the impact of the coronavirus shock: Evidence from real time surveys," Journal of Public Economics, 2020, 189, 104245.

Alon, Titan, Matthias Doepke, Jan Olmstead-Rumsey, and Michèle Tertilt, "The Impact of COVID-19 on Gender Equality," Covid Economics: Vetted and Real-Time Papers, 2020, 4.

_ , _ _, and _, "This Time It's Different: The Role of Women's Employment in a Pandemic Recession," manuscript, Northwestern University November 2020.

Amuedo-Dorantes, Catalina, Miram Marcén Marina Morales, and Almudena Sevilla, "COVID-19 School Closures and Parental Labor Supply in the United States," Discussion paper series 13827, IZA October 2020.

Barkowski, Scott, Joanne Song McLaughlin, and Yinlin Dai, "Young Children and Parents' Labor Supply during COVID-19," manuscript, Clemson University July 2020.

Cajner, Tomaz, Leland D Crane, Ryan A Decker, John Grigsby, Adrian HaminsPuertolas, Erik Hurst, Christopher Kurz, and Ahu Yildirmaz, "The U.S. Labor Market during the Beginning of the Pandemic Recession," Working Paper 27159, National Bureau of Economic Research May 2020.

Carlson, Daniel L., Richard Petts, and Joanna R. Pepin, "Changes in Parents' Domestic Labor During the COVID-19 Pandemic," manuscript, University of Utah October 2020.

Dingel, Jonathan I and Brent Neiman, "How Many Jobs Can be Done at Home?," Working Paper 26948, National Bureau of Economic Research April 2020.

Dingel, Jonathan I., Christina Patterson, and Joseph Vavra, "Childcare Obligations Will Constrain Many Workers When Reopening the US Economy," Working paper 202046, Becker Friedman Institute April 2020.

Heggeness, Misty L., "Estimating the immediate impact of the COVID-19 shock on parental attachment to the labor market and the double bind of mothers," Review of Economics of the Household, 2020, 18 (4), 1053-1078. 
Mongey, Simon, Laura Pilossoph, and Alex Weinberg, "Which Workers Bear the Burden of Social Distancing Policies?," Working Paper 27085, National Bureau of Economic Research May 2020.

Zamarro, Gema and Maria Jose Prados, "Update on Gender Differences in the Impact of COVID-19," CESR report, University of Southern California December 2020. 


\section{Appendix}

\section{A Data}

The Bureau of Labor Statistics' Current Population Survey is the main data source for labor market status, and hours worked and occupation. Parental status is defined by the presence of a child under the age of 17 living in the household. Individuals are considered to work fulltime if they indicate usually working full time and worked full time hours $(35+)$ last week, or if they worked part-time for non-economic reasons last week and usually work full-time.

Household income terciles are defined using the discrete family income variable in the basic monthly CPS files. We set three income groupings that most closely match the income terciles from the continuous income distribution observed in the 2020 ASEC: under $\$ 50,000$, $\$ 50,000$ to $\$ 99,999$, and $\$ 100,000$ and above. ${ }^{15}$

While the BLS has not yet shared details to its method for seasonal adjustment during the pandemic, our method of adjusting 2020 data results in series that are very similar to available published data (see Figure A1). Seasonality is adjusted in a two step procedure. For employment and labor force participation calculations, we first obtain a seasonal adjustment factor for each calendar month of 2019 from the ratio between a series seasonally adjusted with the Census Bureau's X11 seasonal adjustment procedure and the unadjusted data using the data between 2010 and 2019. Second, we apply the obtained seasonal adjustment factors to the corresponding months of 2020. Our seasonal adjustment is slightly modified for hours. Because the CPS collected September data which included labor day, the hours variable had a big dip for the month of September, as many individuals worked one day less than normal during the survey week. The seasonal adjustment procedure that we use accounts for holidays such as labor day. We therefore construct the seasonal adjustment factor for hours from the last year where CPS collected September data during a week that included labor day, which was 2015. To do so, we obtain a seasonal adjustment factor for each calendar month of 2015 from the ratio between a series seasonally adjusted with the Census Bureau's X11 seasonal adjustment procedure and the unadjusted data using the data between 2010 and 2019. Second, we apply the obtained seasonal adjustment factors to the corresponding months of 2020 .

Our measures of occupational flexibility are based on data from the Leave and Job Flexibilities Module, a supplement to the American Time Use Survey (ATUS) which was fielded by the BLS from 2017 to 2018. Select wage and salary workers from the basic ATUS (excluding the self- employed) received the supplement. Among other topics, the module asked

\footnotetext{
${ }^{15}$ Family income tercile cutoffs for the prime-working age population in the 2020 ASEC were approximately: under $\$ 47,000, \$ 47,000$ to $\$ 101,999$, and $\$ 102,000$ and above.
} 
respondents a series of questions related to job flexibility and work schedules. Using these responses, we classify any individual who reported to frequently or occasionally "chang[ing] the times [they] begin and end work" as one with flexible work hours. Similarly, we assume that an individual has the ability to telework if he or she answered "yes" to the question "Can you work at home?" We finally aggregate weighted responses at the 2-digit detailed Standard Occupational Classification (SOC) level. This allows us to calculate both the share of individuals within a given occupation that has flexible work hours and the occupational share that has ability to work from home. ${ }^{16}$

In the HPS the question of school disruption is only asked of individuals with children in the household who will be enrolled in the 2020-2021 school year in grades K-12 in public or private school. We construct our disruption index based on their answer to the question: "How has the coronavirus pandemic affected how the children in this household receive education for the 2020-2021 school year?". We indicate that a household's children have had their schooling disrupted if they answer any of the following: "classes normally taught in person at the school were canceled"; "Classes normally taught in person moved to a distance-learning format using online resources, either self-paced or in real time", or; "Classes normally taught in person moved to a distance-learning format using paper materials sent home to children". ${ }^{17}$ Additionally, this survey was conducted in 3 phases. The second two phases, the first of which started in end of August, ask the questions as posed above. The first phase of the survey, from end of April to end of July word the questions slightly differently, asking if a child was enrolled in school in February 2020 instead of the 2020-2021 school year, and then asking how education was disrupted in general as opposed to the 2020-2021 school year.

\footnotetext{
${ }^{16}$ As a robustness check, we compare employment distributions across occupations by gender between our CPS and ATUS samples. We find no significant differences between the distributions, with no occupational group seeing more than a 2.5 percentage point difference between distribution shares.

${ }^{17}$ We did not include answers to this question of "classes normally taught in person changed in some other way."
} 


\section{B Additional charts and tables}

Table A1: Labor force participation - logit coefficients

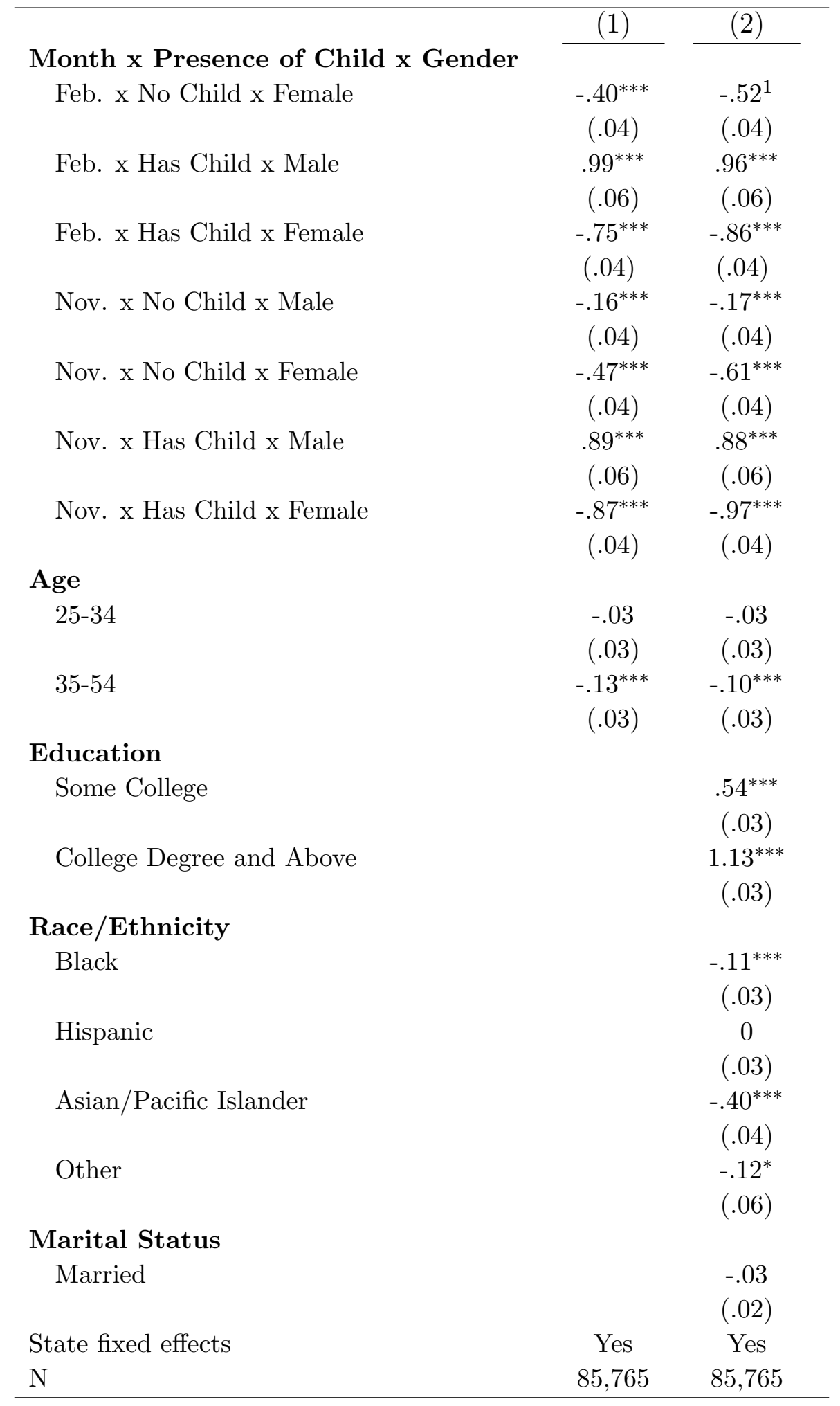

Notes: Statistical significance at the 1, 5, and 10 percent levels indicated by $\left({ }^{* *}\right),\left({ }^{* *}\right)$ and $(*)$, respectively. 


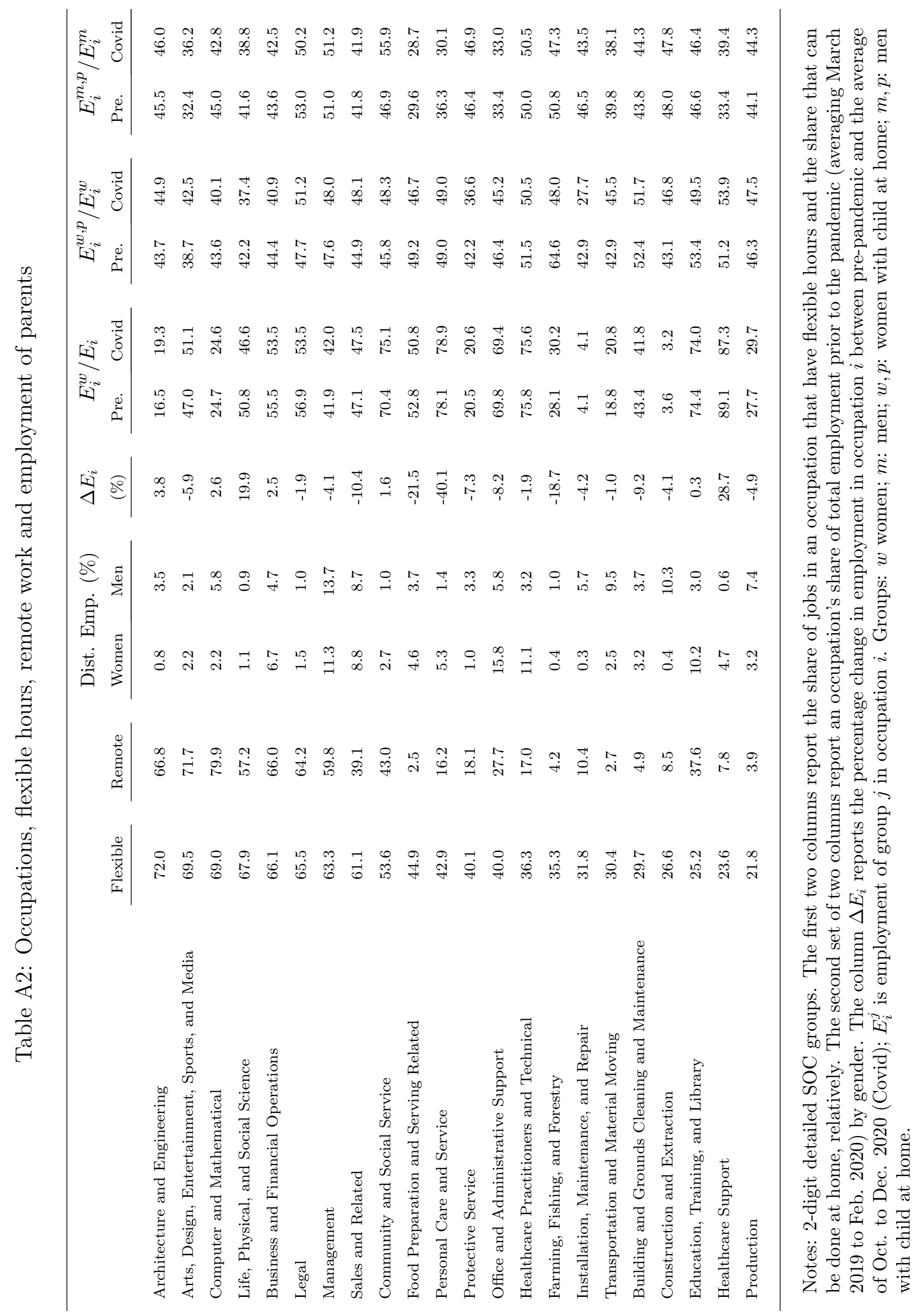


Table A3: Changes in employment to population ratios and participation rates - full sample of prime aged individuals

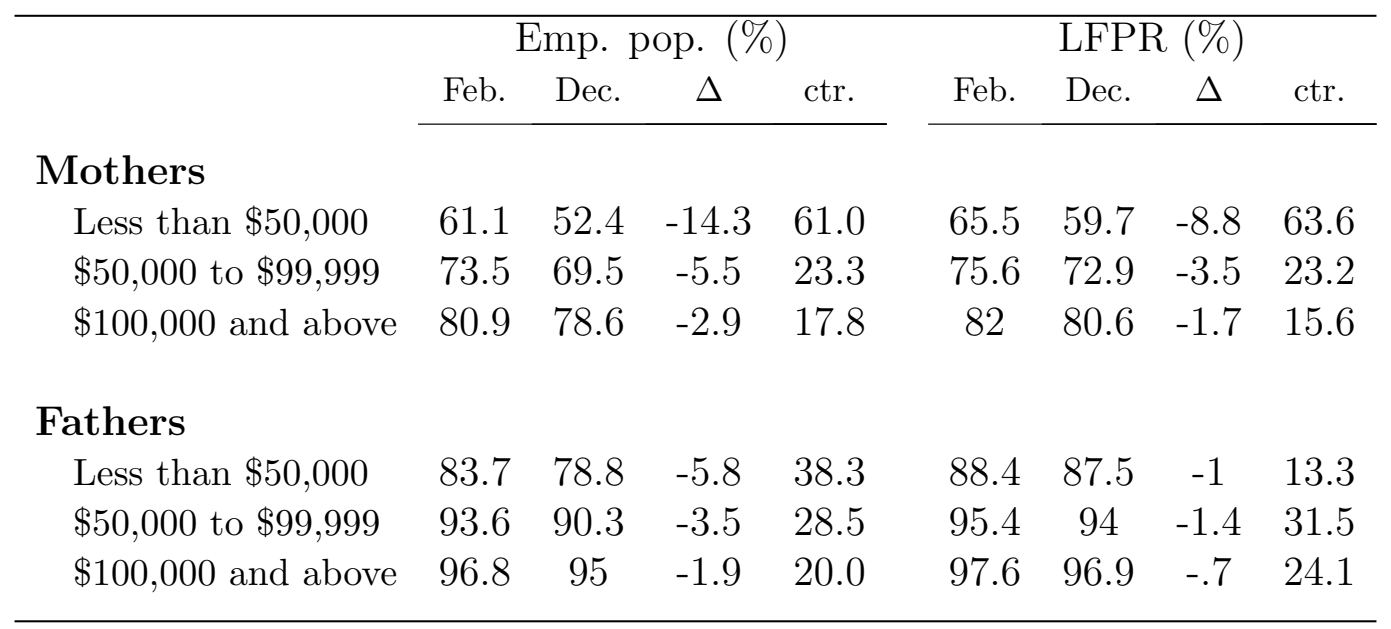

Notes: Authors' calculations using data from the Current Population Survey. A 3-month moving average is applied to the seasonally adjusted data, see data appendix for details. $\Delta$ measures the proportional change between Feb. and Dec. 2020. "ctr.": contribution a subgroup's change in either employment to population ratio or labor force participation rate made to the change in a group's ratio or rate between Feb. and Dec. 2020. 


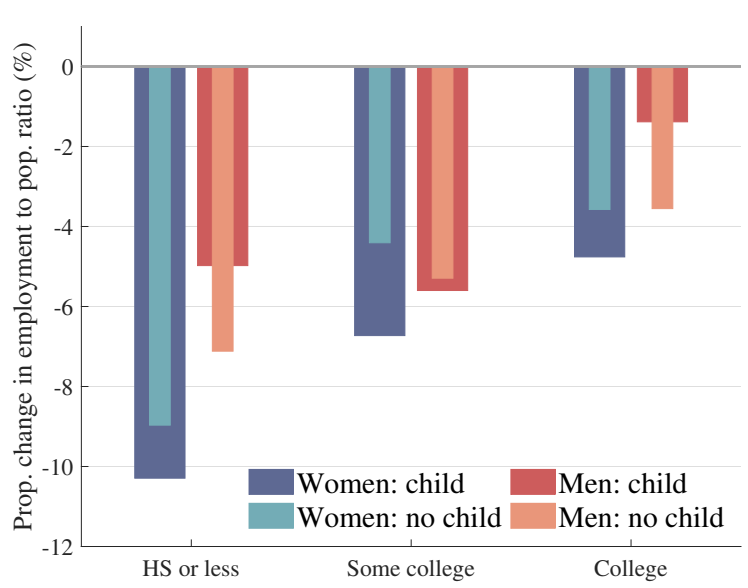

(a) Education and epop

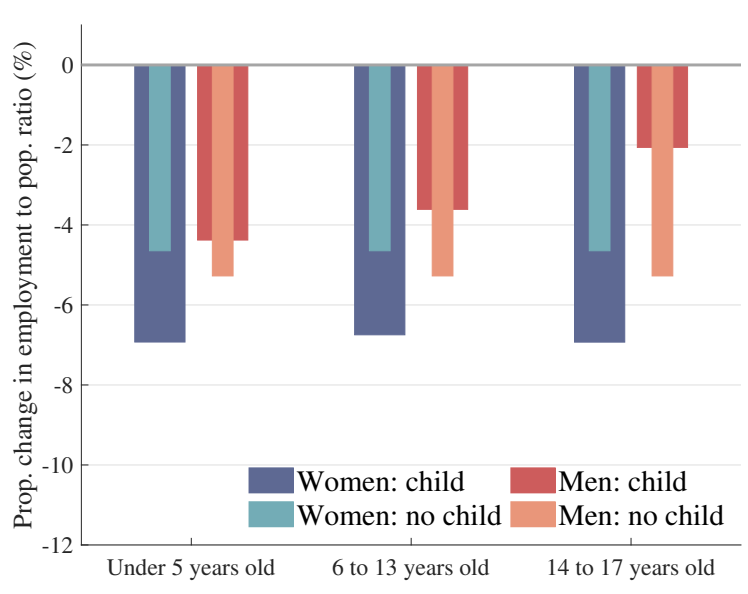

(c) Age of youngest and epop

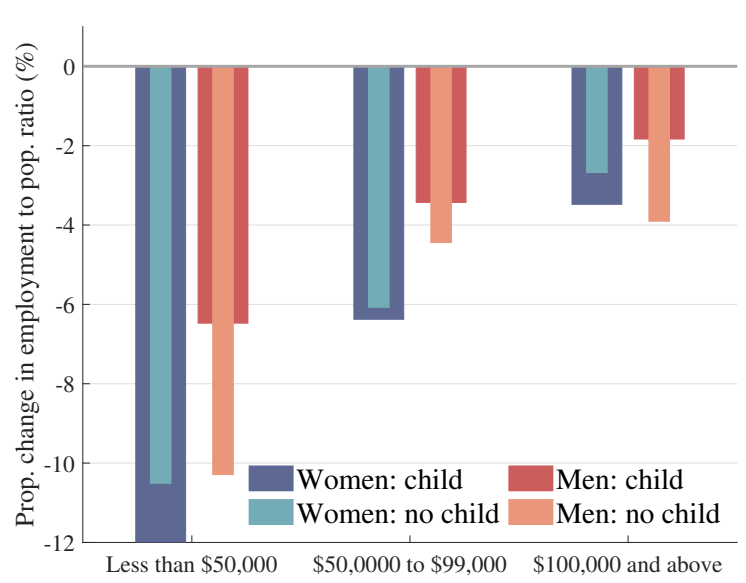

(e) HH income and epop

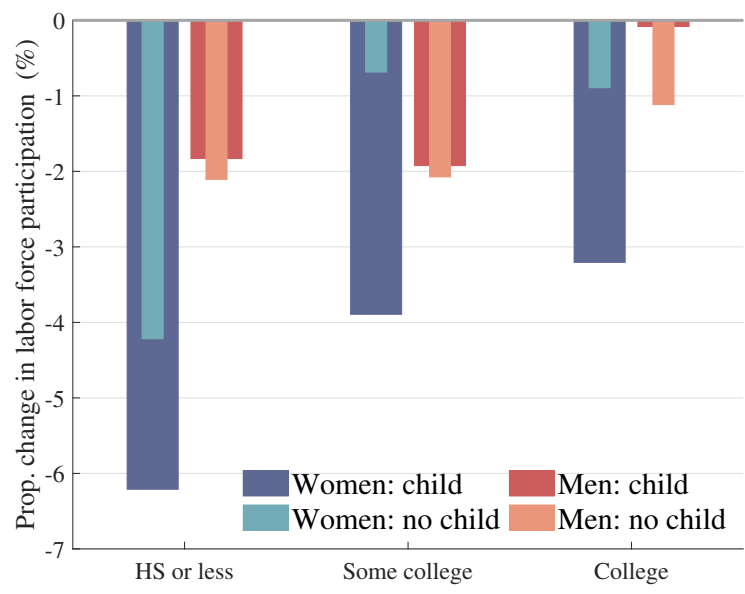

(b) Education and LFPR

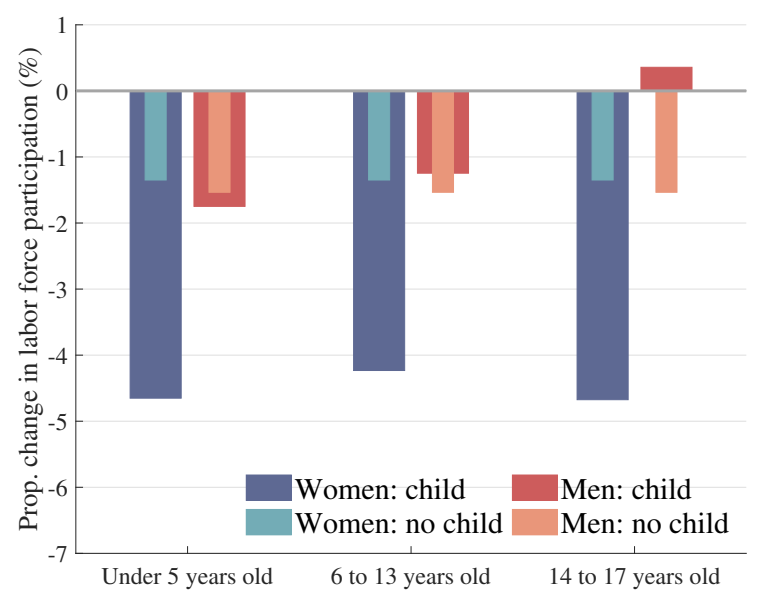

(d) Age of youngest and LFPR

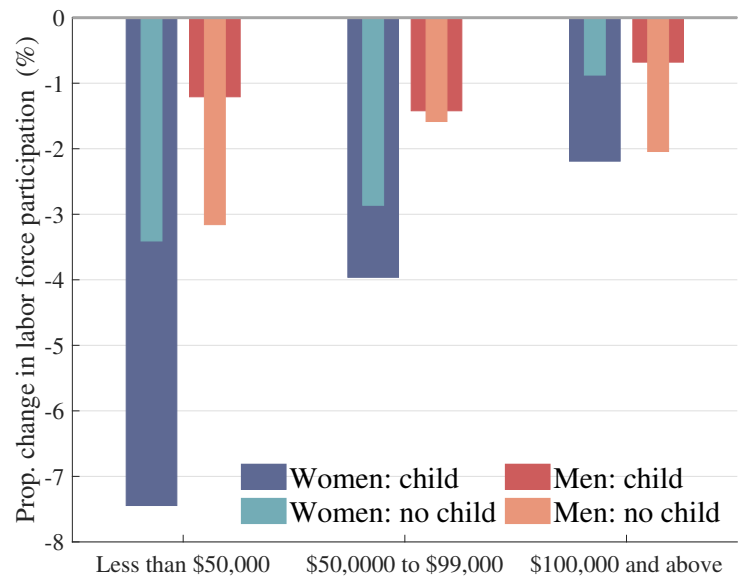

(f) HH income and LFPR

Figure A1: Feb. to Dec. 2020 changes in employment to population ratios and labor force participation rates for prime aged women and men, and conditional on the presence of a child under the age of 17 , for selected demographic groups.

Note: Authors' calculations using data from the Current Population Survey. 3-month moving average on seasonally adjusted data, see data appendix for details. 


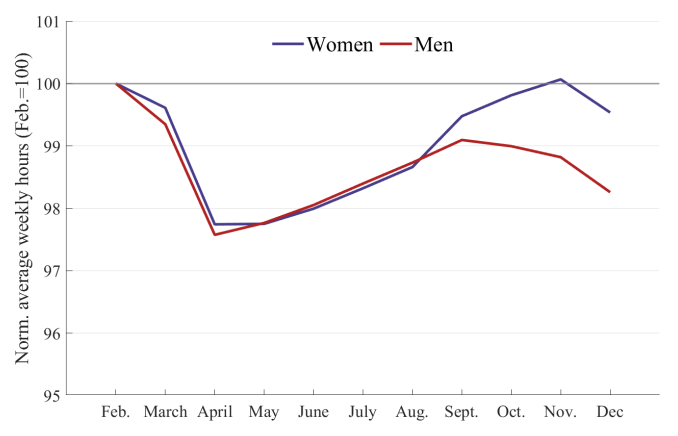

(a) Hours worked per week

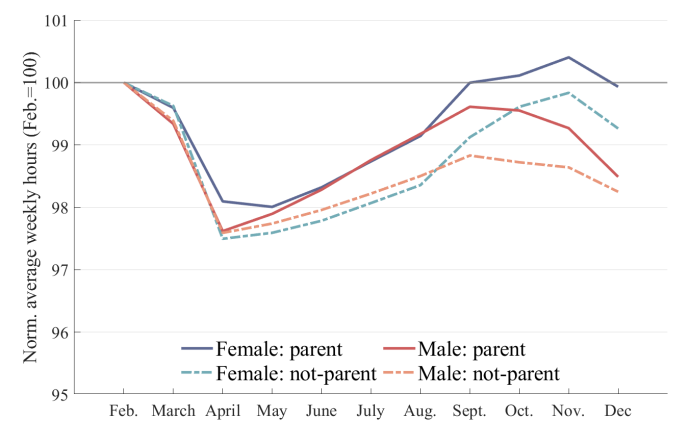

(b) Hours worked per week

Figure A2: Hours worked per week for prime aged women and men employed full time, and conditional on the presence of a child under the age of 17. Normalized to Feb. 2020.

Note: Authors' calculations using data from the Current Population Survey. 3-month moving average on seasonally adjusted data. "Parent" indicates the presence of a child under the age of 17 years old in the household.

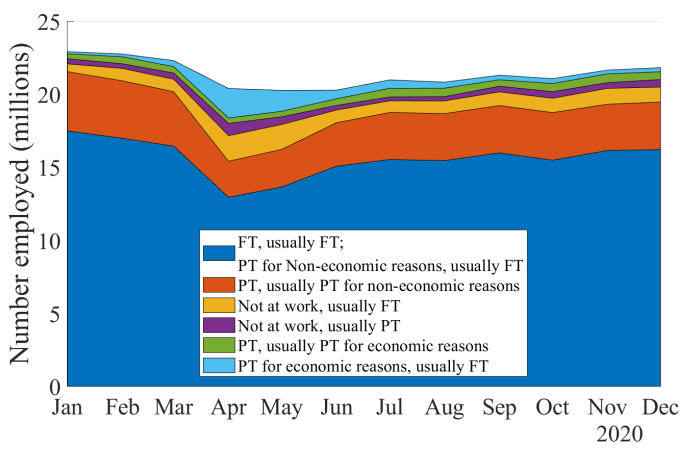

(a) Mothers

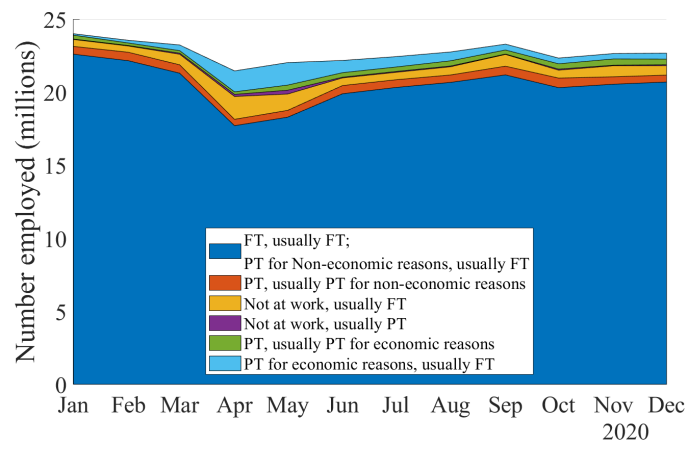

(b) Fathers

Figure A3: Full vs part time employment, prime aged mothers and fathers Note: Authors' calculations using data from the Current Population Survey. Parental status indicates the presence of a child under the age of 17 years old in the household. Seasonally adjusted data. 


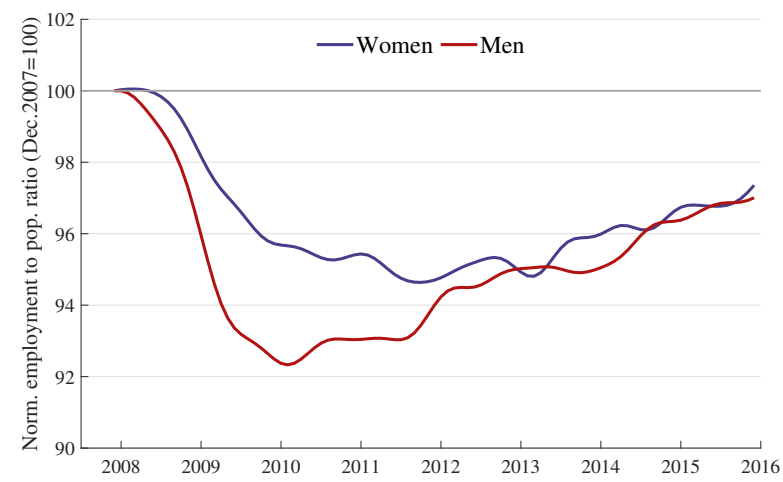

(a) Employment to population ratio

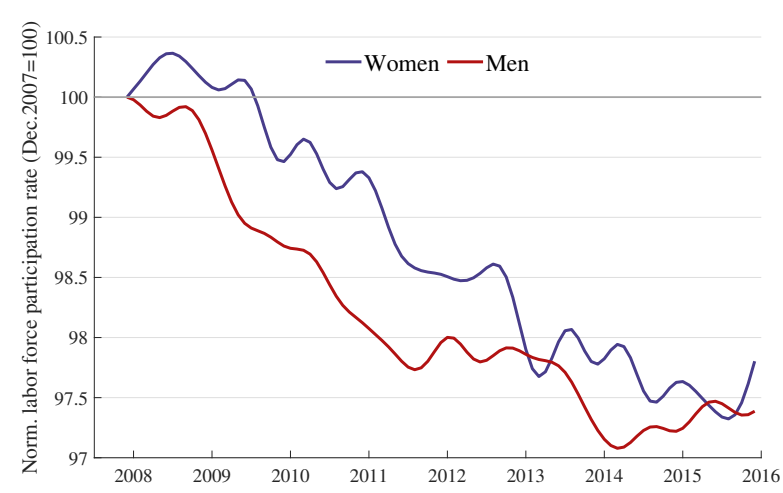

(c) Labor force participation rate

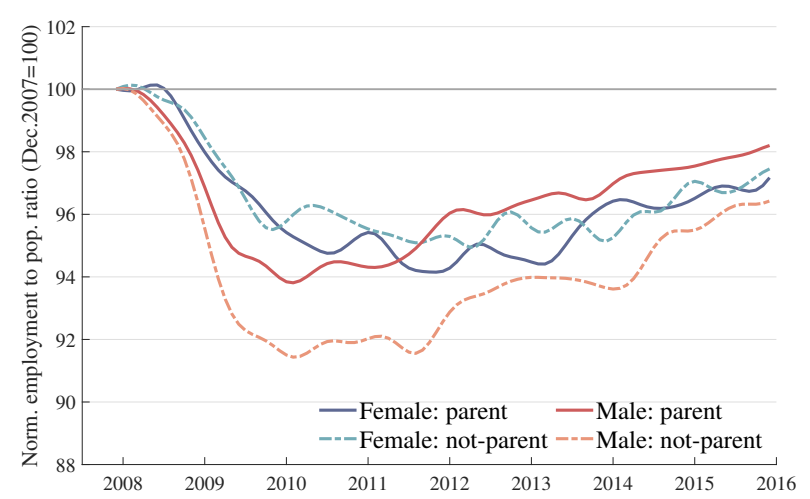

(b) Employment to population ratios

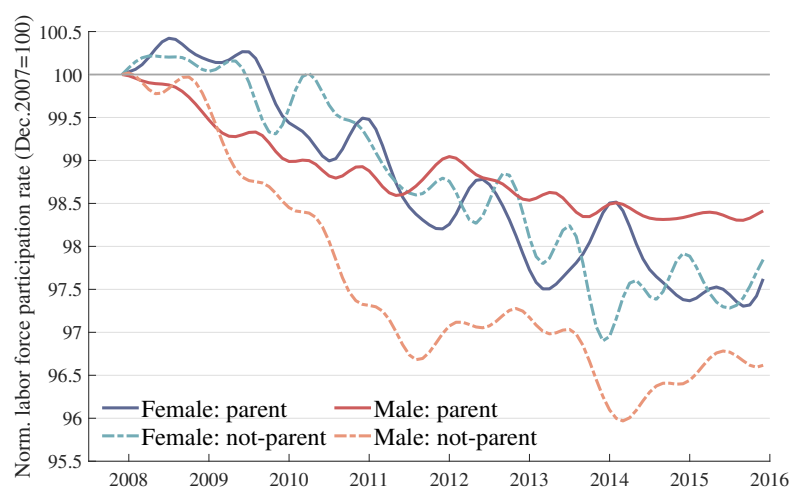

(d) Labor force participation rates

Figure A4: Employment to population ratios and labor force participation rates for prime aged women and men, and conditional on the presence of a child under the age of 17 during the Great Recession. Normalized to Dec. 2007.

Note: Authors' calculations using data from the Current Population Survey. 3-month moving average on seasonally adjusted data, see data appendix for details. "Parent" indicates the presence of a child under the age of 17 years old in the household. 


\section{Telework and flexibility}

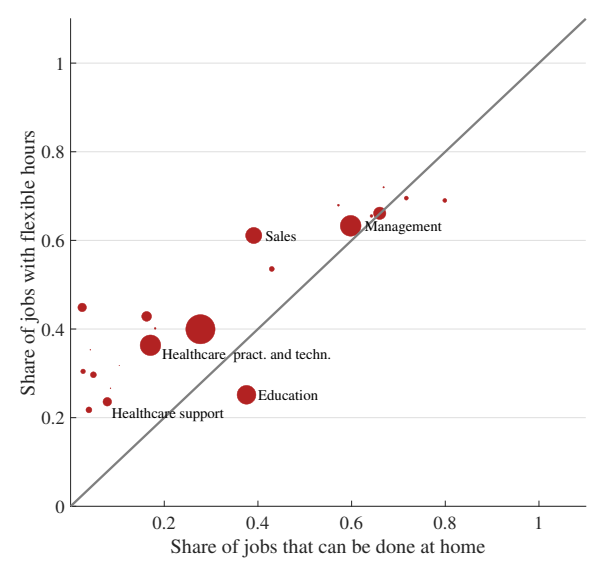

Figure A5: Within occupation share of jobs that can be done from home against jobs with work schedule flexibility

Note: Authors' calculations using data from the Current Population Survey and American Time Use Survey. See data appendix for details.

\section{State LFP rates and school closures}

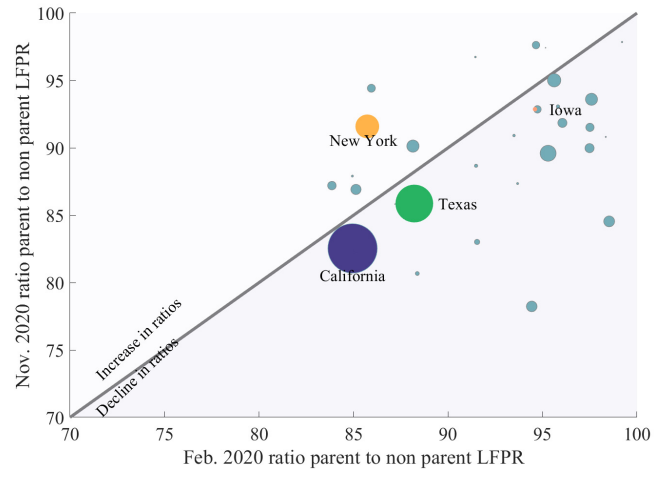

(a) Relative LFPR with children home, Feb. to Nov. 2020

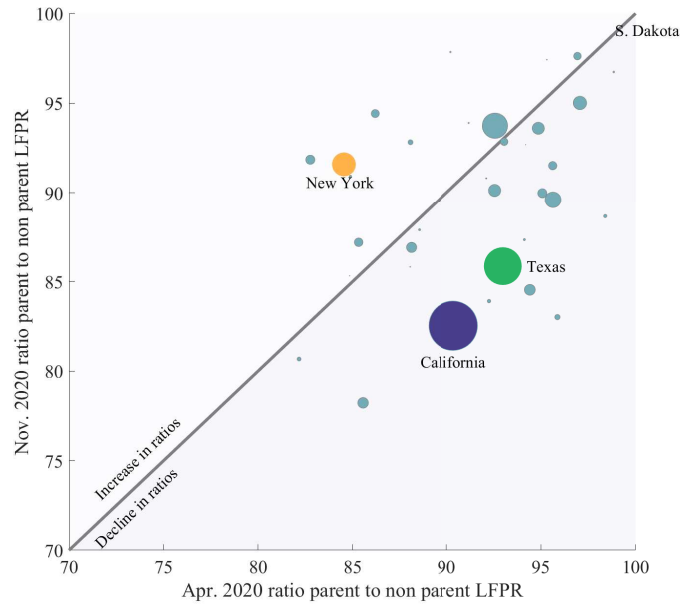

(b) Relative LFPR with children home, April to Nov. 2020

Figure A6: Ratio of mothers to non-parent women LFP rates, prime aged individuals. Note: Authors' calculations using data from the Current Population Survey. 2-month averages on seasonally adjusted data, see data appendix for details. 